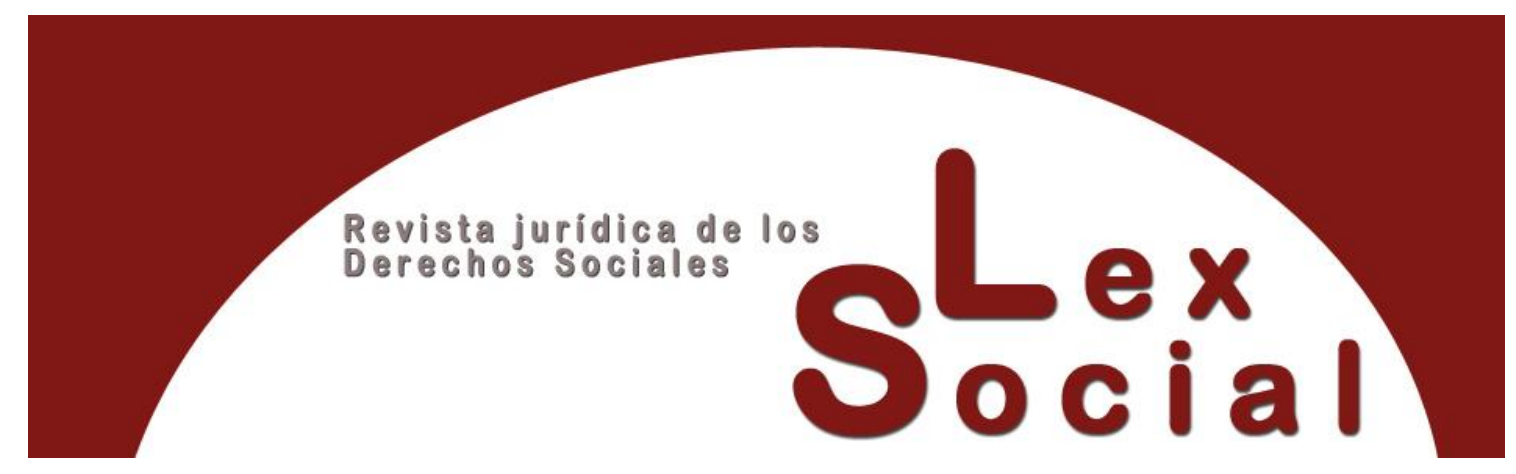

\title{
LOS ACTOS DE COMUNICACIÓN A TRAVÉS DE LEXNET EN EL ORDEN SOCIAL DE LA JURISDICCIÓN
}

\section{THE ACTS OF COMMUNICATION THROUGH LEXNET IN THE SOCIAL ORDER OF THE JURISDICTION}

\author{
MERCEDES LÓPEZ BALAGUER \\ Profesora Titular de Derecho del trabajo y Seguridad Social \\ Universitat de València \\ https://orcid.org/0000-0003-2770-5070
}

Cómo citar este trabajo: López Balaguer, M. (2021). Los actos de comunicación a través de LexNet en el orden social de la jurisdicción. Lex Social: Revista De Derechos Sociales, 11 (2), 98-121. https://doi.org/10.46661/lexsocial.5925

\begin{abstract}
RESUMEN
El presente trabajo analiza las diferentes dudas que está provocando en el orden social de la jurisdicción la aplicación del sistema Lexnet en relación con los actos de comunicación. Se trata de un estudio basado esencialmente en las resoluciones de los Tribunales en la materia, por lo que se centra en abordar todos los temas que en la práctica están planteando problemas para comprobar cuál está siendo el tratamiento de los mismos el ámbito judicial.
\end{abstract}

Palabras Clave: Actos de comunicación, Tutela judicial efectiva, LexNet, Orden Social

\section{AbSTRACT}

This paper analyzes the different doubts that the application of the Lexnet system is causing in the social order of the jurisdiction. It is a study based essentially on

\section{(cc) EY-NC-SA}


the decisions of the Courts on the matter, so it focuses on addressing all the issues that are being raised in practice to verify what the judicial field is treating them.

KEYWORDS: Acts of communication, Effective judicial protection, LexNet, Social Order

\section{SUMARIO}

I. Introducción: el carácter relevante de los actos de comunicación en el Orden Social y la aplicación de las nuevas tecnologías de la comunicación

II. Los medios electrónicos como vía exigida en los actos de comunicación

III. El lugar de los actos de comunicación en la jurisdicción social

1. Sujetos obligados a la comunicación electrónica

2. Sujetos no obligados a la comunicación electrónica

3. El primer emplazamiento o citación del demandado

VI. La forma de presentación de los escritos y documentos

V. El tiempo para la realización de los actos de comunicación

\section{Introducción: el carácter relevante de los actos de comunicación en el Orden Social y la aplicación de las nuevas tecnologías de la comunicación}

La especial relevancia de los actos de comunicación se destaca en la STC 32/2019, de 28 de febrero, que hace hincapié en los actos de emplazamiento, citación y notificación. Según se concluye en la citada resolución la falta o deficiente realización de estos actos de comunicación, "siempre que se frustre la finalidad con ellos perseguida, coloca al interesado en una situación de indefensión que vulnera el derecho de defensa" ${ }^{1}$. En este sentido, el carácter relevante de los actos de comunicación citados se debe a que se trata de instrumentos que facilitan la defensa en el proceso de los derechos e intereses cuestionados.

De este modo, se insiste en la sentencia en la necesidad de que la falta o el defecto del acto de comunicación coloquen a la parte en situación de indefensión. Con ello se debe matizar que no puede considerarse que cumple con esta condición la falta de comunicación que pueda traer su causa en la acción o inacción de la parte afectada, que se pueda haber situado, voluntaria o negligentemente, al margen del proceso pese a tener conocimiento del mismo por otros medios distintos.

\footnotetext{
${ }^{1}$ En el mismo sentido, entre otras muchas, SSTC115/1988, de 10 de junio; 195/1990, de 29 de noviembre; 326/1993, de 8 de noviembre; 77/1997, de 21 de abril; 219/1999, de 29 de noviembre; 128/2000, de 16 de mayo; 61/2010, de 18 de octubre; 30/2014, de 24 de febrero y 169/2014, de 22 de octubre.
} 
No obstante, "esta negligencia, descuido o impericia imputables a la parte, o el conocimiento extraprocesal de la causa judicial tramitada inaudita parte, no puede fundarse sin más en una presunción cimentada en simples conjeturas, sino que debe acreditarse fehacientemente para que surta su efecto invalidante de la tacha de indefensión, pues lo presumido, es justamente, el desconocimiento del proceso si así se alega" (STC 181/2015, de 7 de septiembre).

Así pues, partiendo del objetivo fundamental de amparar este derecho de las partes a la tutela judicial efectiva (art. $24 \mathrm{CE}$ ), hemos de señalar que, concretamente en el proceso laboral, el legislador se detiene en los artículos 53 a 62 Ley 36/2011, de 10 de octubre, reguladora de la jurisdicción social (en adelante, LRJS) en tres aspectos fundamentales de los actos de comunicación que son el lugar, la forma y el tiempo de los mismos. Estos tres aspectos, como es sabido, en los últimos años han adquirido una nueva dimensión por el impacto de las nuevas tecnologías de la información y de la comunicación. Se trata concretamente de la dimensión telemática que se implantó ya en el año 2007 con la aplicación del sistema LexNet como medio de transmisión seguro de la información basado en el correo electrónico y en la firma electrónica reconocida y que se introdujo con el RD 84/2007, de 26 de enero, sobre implantación en la Administración de Justicia del sistema informático de telecomunicaciones LexNet para la presentación de escritos y documentos, el traslado de copias y la realización de actos de comunicación procesal por medios telemáticos.

Posteriormente, la Ley 18/2011, de 5 de julio, reguladora del uso de las tecnologías de la información y la comunicación en la Administración de Justicia, definió un marco general del uso de medios informáticos en la Administración de Justicia y dedicó el Capítulo III del Título IV al registro de escritos, las comunicaciones y las notificaciones electrónicas. Esta norma fue desarrollada en 2015 por el RD 1065/2015, de 27 de noviembre, sobre comunicaciones electrónicas en la Administración de Justicia en el ámbito territorial del Ministerio de Justicia y por el que se regula el sistema LexNet.

La DA $7^{a}$ de la Ley 18/2011, proclamó desde el inicio de la regulación de la dimensión telemática de los actos de comunicación, el carácter transversal de la misma para todos los órdenes jurisdiccionales, completando la legislación vigente en lo concerniente al uso de las tecnologías de la información y la comunicación en la Administración de justicia. Este carácter transversal viene establecido también en los arts. 230 y 271 de la LOPJ. No obstante, si revisamos los preceptos de la LRJS citados antes en relación con los actos de comunicación -arts. 53 a 62-, podemos comprobar que no se recoge en los mismos la referencia a la dimensión telemática a través del sistema LexNet.

En relación con esta ausencia de referencia legal específica en la norma procesal laboral hay que interpretar, de acuerdo con la doctrina clásica del TC, que la función y diseño común de determinadas actuaciones judiciales se encuentra perfilado en la LOPG y en las normas procesales propias de cada orden judicial. Esta norma en el orden social es la 
actual LRJS, pero "sin olvidar la función supletoria de la Ley de enjuiciamiento civil por su carácter matriz y residual respecto de los demás sectores. Los tres componen el grupo normativo con relevancia para perfilar el derecho fundamental [a la tutela judicial efectiva]" (STC 118/1993, de 29 de marzo).

En este sentido, el ATS de 6 de febrero de 2019, rec. 49/2018, resulta muy clarificador cuando concluye que "el hecho de que la Ley Reguladora de la Jurisdicción Social no haga mención expresa en su articulado al sistema LexNet, no debe entenderse en absoluto como una singularidad excluyente, al no apreciarse justificación alguna de tal interpretación, sino que más bien ha de entenderse su vigencia en el ámbito de la jurisdicción social por vía de la aplicación supletoria de aquella norma procesal general, la Ley de Enjuiciamiento Civil, en la que como se ha visto se han insertado con precisión las peculiaridades técnicas y los efectos procesales de su utilización, posibilitando su aplicación generalizada y homogénea para los órganos judiciales, profesionales y particulares, con el sentido de transversalidad predicado desde el principio para este medio técnico. No puede por tanto entenderse excluida su aplicación por los órganos judiciales de la jurisdicción social, porque además las regulaciones que se contienen en la Ley Reguladora de la Jurisdicción Social y en la Ley de Enjuiciamiento Civil no son en absoluto incompatibles".

Así pues, en el orden social de la jurisdicción, la regulación de la LEC va a resultar aplicable en todas aquellas cuestiones referidas a los actos de comunicación. Y ello, dado que, tanto de manera genérica, a través de la DF $4^{\mathrm{a}}$ LRJS, como con carácter específico en materia de actos de comunicación, a través de los arts. 53.1 y 56.5 LRJS, se configura expresamente una remisión al art. 162 LEC cuando la comunicación tenga lugar utilizando medios electrónicos, telemáticos, infotelecomunicaciones o de otra clase semejante (ATS de 29 de noviembre de 2016, Rec. 37/2016: el entronque procesal de tales normas se produce inicialmente a través de la Ley 41/2007, de 7 de diciembre, por la que se modifica la Ley 2/1981, de 25 de marzo, de Regulación del Mercado Hipotecario y otras normas del sistema hipotecario y financiero, de regulación de las hipotecas inversas y el seguro de dependencia y por la que se establece determinada norma tributaria, que en su Disposición Final sexta modifica la LEC, modificación que afectó, entre otros, a los arts. 135, 151 y 162; siendo finalmente la Ley 42/2015 de 5 de octubre, de reforma de la Ley 1/2000, de 7 de enero, de Enjuiciamiento Civil, la que vino a consolidar la normativa procesal actual en este materia).

Partiendo de este recorrido normativo seguido para la implantación del sistema LexNet, en el presente artículo nos vamos a centrar en el análisis de las incidencias de la implementación de este sistema LexNet estudiando su aplicación a través de los pronunciamientos judiciales recaídos en relación con los aspectos esenciales de los actos de comunicación. Y es que no podemos obviar el impacto de la aplicación de la tecnología en estos actos y el imparable proceso en el que nos encontramos en el ámbito de la justicia por lo que a la digitalización se refiere. En este sentido, como se ha puesto de manifiesto, 
la intensificación del uso de la tecnología y la digitalización del proceso es imparable en sistema de justicia. Sostener lo contrario supone desconocer los avances tecnológicos del momento. Otra cosa es que los que se estén llevando a cabo sean adecuados y suficientes. Ahora bien, los países que invierten adecuada y organizadamente en infraestructuras y tecnología de la información consiguen hacer más eficiente su sistema y reducir plazos procesales, así como optimizar la asignación de recursos ${ }^{2}$.

En España parece que la percepción de los profesionales de la justicia es la de que el sistema Lexnet, con dificultades y problemas, es un sistema generalizado con la mayor parte de los operadores jurídicos, y que desde luego es eficaz y deseado por los órganos judiciales para que se generalice ${ }^{3}$.

\section{Los medios electrónicos como vía exigida en los actos de comunicación}

Tal y como hemos señalado, el RD 1065/2015 desarrolla lo previsto la Ley 18/2011 en lo relativo a las comunicaciones y notificaciones electrónicas, así como a la presentación electrónica de escritos, documentos u otros medios o instrumentos y al traslado de copias. Esta norma reglamentaria, al igual que el art. 273 LEC, delimita en sus arts. 4 y 5, desde un punto de vista subjetivo el alcance de la obligatoriedad del uso de los canales electrónicos de comunicación. Concretamente, según lo previsto en estos preceptos, se entiende que quedan obligados los siguientes sujetos:

- Todos los abogados, procuradores, graduados sociales, Abogados del Estado, Letrados de las Cortes Generales, de las Asambleas Legislativas y del Servicio Jurídico de la Administración de la Seguridad Social, de las demás Administraciones Públicas, de las Comunidades Autónomas o de los Entes Locales, así como los Colegios de Procuradores y administradores concursales.

- Todos los integrantes de los órganos y oficinas judiciales y fiscales.

- Las personas jurídicas.

- Las entidades sin personalidad jurídica.

- Quienes ejerzan una actividad profesional para la que se requiera colegiación obligatoria para los trámites y actuaciones que realicen con la Administración de Justicia en ejercicio de dicha actividad profesional.

- Los notarios y registradores.

- Quienes representen a un interesado que esté obligado a relacionarse electrónicamente con la Administración de Justicia.

- Los funcionarios de las Administraciones Públicas para los trámites y actuaciones que realicen por razón de su cargo.

\footnotetext{
${ }^{2}$ En este sentido, MARTÍNEZ MOYA, J., "Las comunicaciones electrónicas procesales a través del sistema Lexnet y la potestad de control de los tribunales para garantizar el derecho a la tutela judicial efectiva. La tecnología como instrumento al servicio de la justicia y de los justiciables", Revista de Jurisprudencia Laboral, Núm. 4, 2019, p. 9

${ }^{3}$ BARRIO CALLE, M.A., "Algunas distorsiones en los actos de comunicación telemáticos en el proceso laboral", Revista Acta Judicial, n² 2, julio, 2018, p. 84
} 
- Y los que legal o reglamentariamente se establezcan.

No obstante, esta obligación de comunicación electrónica no es absoluta ni desde el punto de vista subjetivo, ni desde una perspectiva objetiva.

En primer lugar, el art. 4.1 RD 1065/2015, al igual que el art. 273.2 LEC, deja libertad a las personas que no estén asistidas o representadas por profesionales de la justicia para elegir, en todo momento, de qué modo quieren comunicarse con la Administración de Justicia y la forma de recibir las comunicaciones y notificaciones de la misma sea o no por canales electrónicos. En el ámbito social de la jurisdicción, en la instancia, como es sabido, el art. 21.1 LRJS contempla el carácter facultativo de la defensa por abogado o la representación técnica por graduado social. De este modo, cabe destacar que en nuestro ámbito es posible que la obligación de comunicación electrónica no siempre entre en juego. Por ello, conviene tener en cuenta la regulación aplicable en relación con los actos de comunicación tanto en la LRJS como en la LEC.

En segundo lugar, cuando se trata del primer emplazamiento o citación del demandado, el régimen jurídico específicamente aplicable viene establecido en los apartados 1, 2 y 3 del art. 155 LEC y se limita expresamente a la comunicación por remisión al domicilio de los litigantes.

Así pues, aun en la actual situación de obligatoriedad generalizada de las comunicaciones electrónicas, lo cierto es que el lugar de los actos de comunicación sigue resultando relevante (III). Por otro lado, ocurre lo mismo con la forma de comunicación que adquiere una dimensión diferente (IV). Y, finalmente, el tiempo de los actos de comunicación también debe ser reformulado ante la implantación de la comunicación telemática (V).

\section{El lugar de los actos de comunicación en la jurisdicción social}

Según lo dispuesto por los arts. 55 y 53 LRJS, respectivamente, el lugar para la realización de los actos de comunicación podrá ser tanto la Oficina Judicial como el propio domicilio de las partes. Respecto de la comunicación en el local de la Oficina Judicial, el art. 55 LRJS señala que "las citaciones, notificaciones, emplazamientos y requerimientos se harán en el local de la Oficina judicial, si allí comparecieren por propia iniciativa los interesados $\mathrm{y}$, en otro caso, en el domicilio señalado a estos efectos".

En relación con las comunicaciones hechas en el domicilio de las partes, el art. 53 LRJS establece que serán las partes, y en su caso los profesionales designados quienes señalarán un domicilio y datos completos para la práctica de los datos de comunicación. El domicilio y los datos de localización facilitados con tal fin surtirán plenos efectos y las notificaciones en ellos intentadas sin efecto serán válidas hasta tanto no sean facilitados otros datos alternativos, siendo carga procesal de las partes y de sus representantes mantenerlos actualizados. Asimismo, deberán comunicar los cambios relativos a su número de teléfono, fax, dirección electrónica o similar, siempre que estos últimos estén 
siendo utilizados como instrumentos de comunicación con el tribunal. De este modo, la ley obliga a que este "domicilio" de notificación sea para siempre, y, es más, insiste en ello, señala que si no ha dicho lo contrario es válida la notificación allí efectuada. Es más, se les "obliga" a comunicar cualquier cambio en el destino de la notificación cualquiera que sea el medio que se utilizara con anterioridad. Esto supone que no se puede dejar al arbitrio de la parte cómo quiere que le notifiquen en cada momento y es importante tener en cuenta esto, pues puede significar que no ha de resultar de aplicación lo dispuesto antes de estas modificaciones en otros artículos de la ley, o que la regulación no es coherente y apropiada a las comunicaciones telemáticas ${ }^{4}$.

Delimitado el lugar de los actos de comunicación en los términos señalados, los arts. 56 a 59 LRJS regulan las diferentes formas para su realización, señalando, en primer lugar, que será el correo certificado con acuse de recibo la forma en la que los mismos se harán, pudiéndose, en su caso, utilizar también el servicio de telégrafo, fax, correo electrónico o cualquier otro medio idóneo de comunicación o de transmisión de textos si los interesados facilitasen los datos para ello; en segundo lugar, si no fuese posible la comunicación por esta vía, el trámite a seguir será la entrega de copia de la resolución o de cédula al destinatario - arts. 57 y 58 LRJS — ; y, finalmente, cuando intentada la comunicación a través de las vías anteriores, no se hubiese podido realizar porque no conste el domicilio del interesado o se ignore su paradero, se consignará por diligencia y se ordenará la notificación por medio de edictos — art. 59 LRJS—, dado que "pesa sobre los órganos judiciales la responsabilidad de procurar el emplazamiento o citación personal de los demandados, siempre que sea factible, asegurando de este modo que puedan comparecer en el proceso y defender sus posiciones frente a la parte demandante" (entre otras, SSTC 126/2006, de 24 de abril; 76/2006, de 13 de marzo).

Pues bien, como hemos dicho ya, con la implantación del sistema LexNet no cabe duda de que el lugar de los actos de comunicación ha adquirido una nueva dimensión no locativa desde una perspectiva geográfica. El lugar físico de la comunicación es hoy día, salvo las excepciones que veremos, la sede telemática. En este sentido, tal y como dispone el art. 152.2 LEC, los actos de comunicación se practicarán por medios electrónicos en todo caso:

- Cuando los sujetos intervinientes en un proceso estén obligados al empleo de los sistemas telemáticos o electrónicos existentes en la Administración de Justicia (1).

- Cuando los sujetos intervinientes, sin estar obligados, opten por el uso de esos medios (2).

\section{Sujetos obligados a la comunicación electrónica}

Los sujetos obligados a la comunicación electrónica por imperativo legal tienen que actuar en el proceso laboral sirviéndose de las vías tecnológicas y, de acuerdo con lo

\footnotetext{
${ }^{4}$ BARRIO CALLE, M.A., "Algunas distorsiones en los actos de comunicación telemáticos...”, op. cit., p. 74.
} 
previsto en el art. 152.2 LEC, también se reconoce que los actos de comunicación se deben practicar por medios electrónicos. Esto supone que el domicilio a efectos de notificaciones sea la Dirección Electrónica Habilitada (DEH), que se configura como una obligación legal de las personas jurídicas y de las entidades sin personalidad jurídica que deban intervenir y recibir actos de comunicación por medios electrónicos ${ }^{5}$.

En relación con los sujetos obligados, de manera categórica el TS ha considerado que "la inherente automaticidad de las comunicaciones LexNet deja sin razón alguna tal requisito geográfico (ATS de 5 de marzo de 2019, Rec. 54/2018). Concretamente, en relación con la interpretación del vigente art. 221.1 LRJS, sostiene que podemos estar ante una previsión que "podría haber quedado vacía de sentido, o en todo caso, que ha sido tácita y parcialmente derogada, evidentemente no por el RD 1065/2015, que no podía hacerlo por un básico principio de jerarquía normativa, pero sí al menos por la Ley 42/2015 de reforma de la Ley de enjuiciamiento civil, y ello con la excepción de que tal domicilio designado a efectos de notificaciones fuese el de otro letrado o un procurador (y no necesariamente de Madrid, porque la inherente automaticidad de las comunicaciones LexNet deja sin razón alguna tal requisito geográfico)”. De esta forma no sería exigible ya a los letrados que presentan su escrito de preparación de recurso de unificación de doctrina el ofrecer un domicilio a efectos de notificaciones en la capital, cuando dichas notificaciones han de efectuarse obligatoriamente por el conducto del sistema LexNet y con el propio letrado actuante. En cualquier caso, como lo cierto es que el art. 221.1 LRJS, aunque se considerase al menos en parte derogado tácitamente, "sigue generando en el profesional la creencia y confianza legítima de que tiene tal posibilidad -más bien obligación- de designar un domicilio en Madrid a efectos de notificaciones", debe reinterpretarse por lo que a las condiciones de su aplicación práctica se refiere (ATS de 18 de diciembre de 2018, Rec. 1461/2017):

- Por una parte, "en el caso hipotético de designar el domicilio de un particular, no sería válida tal designación: en este supuesto el Tribunal debería comunicar al letrado tal imposibilidad y seguir notificándole a él vía LexNet”.

- Por otra parte, en cambio, si de acuerdo con lo previsto en el art. 221.1 LRJS se designa a efectos de notificaciones el despacho de otro letrado o el de un procurador; o, en su caso, si se designa a un graduado social a efectos de notificaciones vía LexNet, "las notificaciones LexNet efectuadas sólo podrían considerarse válidas de haberse efectuado por el Tribunal en el despacho designado y no en otro distinto, mientras, claro está, no conste en la Secretaría del Tribunal la negativa del otro profesional a asumir tales notificaciones. Y ello por cuanto el juego combinado del art. 221.1 Ley Reguladora de la Jurisdicción Social y la normativa LexNet exige interpretar que cuando nuestra ley procesal se refiere a la designación de un domicilio a efecto de notificaciones en Madrid, está hoy en realidad aludiendo a la posibilidad de designación de otro buzón virtual LexNet (de otro letrado o un procurador), sin que deba olvidarse, por otro lado, que las

${ }^{5}$ Ibídem, p. 79. 
sustituciones y autorizaciones de unos a otros los profesionales de la justicia están contempladas también en el RD 1065/15 en su art. 19 ("... El titular de cada buzón podrá vincular al mismo a otros usuarios como autorizados para que en su nombre puedan realizar con plenitud de efectos jurídicos los envíos de documentación o recepción de actos de comunicación desde ese buzón") por más que se trate de decisiones de sustitución entre ellos y sin reflejo en el procedimiento -esto es, que no imponen cambio de buzón LexNet-, que en nuestro caso vendrían autorizadas por la previsión legal tantas veces citada".

En relación con este Auto, tal y como se ha considerado ${ }^{6}$, la conclusión no puede ser otra que la de entender que es necesario adaptar todo el conjunto de la LRJS a la realidad actual de notificaciones a través de Lexnet, y telemáticos en general.

\section{Sujetos no obligados a la comunicación electrónica}

Tal y como hemos señalado, el art. 4.1 RD 1065/2015, al igual que el art. 273.2 LEC, señalan que las personas físicas que actúan como parte en un proceso, sin requerir de un representante procesal por no exigirlo la legislación procesal correspondiente, no tienen obligación de comunicarse electrónicamente con el órgano judicial. Para estos sujetos en realidad la comunicación electrónica no es un deber, sino que se configura "como un derecho" (STC 6/2019, de 17 de enero).

En relación con los sujetos no obligados, el art. 56 LRJS en sus apartados primero, segundo y tercero, dispone, como hemos visto, que las citaciones, notificaciones y emplazamientos podrán comunicarse por el correo certificado con acuse de recibo como vía inicial de comunicación a seguir. Deja el precepto al margen de este procedimiento la comunicación de requerimientos, dado que cuando los mismos son notificados sí cabe respuesta del interesado, de acuerdo con lo previsto por el art. 60.1 LRJS. Pues bien, las comunicaciones realizadas por correo certificado quedan sujetas al cumplimiento de varios requisitos:

- $\quad$ Que dé fe el LAJ en los autos del contenido del sobre remitido y se una a ellos el acuse de recibo.

Que consten en el exterior del sobre las advertencias contenidas en el art. 57.3 LRJS dirigidas al receptor para el caso de que no fuera el interesado ("Se hará saber al receptor que ha de cumplir el deber público que se le encomienda; que está obligado a entregar la copia de la resolución o la cédula al destinatario de esta, o a darle aviso si sabe su paradero, con advertencia de que puede ser sancionado con multa de veinte a doscientos euros si se niega a la recepción o no hace la entrega a la mayor brevedad; que ha de comunicar a la Oficina judicial la imposibilidad de entregar la comunicación al interesado, y que tiene derecho al resarcimiento de los gastos que se le ocasionen").

Que en el documento de acuse de recibo se haga constar la fecha de la entrega, debiendo ser firmado por el funcionario de Correos y el receptor. En el caso de

\footnotetext{
${ }^{6}$ Ibídem, p. 76.
} 
que este no fuera el interesado se consignará su nombre, documento de identificación, domicilio y su relación con el destinatario.

Así pues, el cumplimiento de todos los requisitos reseñados es fundamental para que la comunicación por correo certificado se entienda realizada conforme a derecho y, por tanto, de acuerdo con el derecho a la tutela judicial efectiva del destinatario.

En todo caso, hay que recordar que el art. 52.2 LRJS establece una importante obligación de diligencia de las partes que deberán comunicar en su caso cualquier cambio de domicilio al órgano judicial, ya que la notificación intentada sin efecto en la dirección facilitada por las partes será válida en todo caso hasta que no notifiquen estas la modificación de la misma.

Respecto de la recepción de la notificación por correo certificado, ha de puntualizarse que su validez dependerá de que se lleve a cabo con las garantías suficientes "siendo preciso, para ello, que los órganos judiciales no otorguen mecánicamente un valor absoluto al simple contenido formal de la diligencia de notificación, prescindiendo de cualquier enjuiciamiento sobre los motivos alegados por la parte acerca de la no recepción en plazo de la notificación. En efecto, los órganos judiciales no pueden presumir, sin lesionar el derecho a la tutela judicial efectiva (art. 24.1 CE), que las notificaciones realizadas a través de terceras personas hayan llegado al conocimiento de la parte interesada cuando esta cuestiona su entrega misma, pues, a la vista de las circunstancias del caso, de las alegaciones formuladas y de la prueba que pueda ser aportada, se encuentran obligados a emitir un pronunciamiento expreso sobre la posibilidad de que haya existido o no una falta de entrega que haya impedido al interesado utilizar los medios de defensa para cuyo ejercicio efectivo establece el Ordenamiento un determinado plazo" (STC 42/2002, de 25 de febrero). Así pues, no será admisible la comunicación por correo certificado a un tercero:

- No constando en el acuse de recibo del envío por correo certificado de la citación para los actos de conciliación y juicio, el número del DNI de la persona receptora ${ }^{7}$.

- Cuando no se haga constar en el acuse de recibo la identificación clara del receptor de la notificación, ni su relación con la empresa destinataria de la misma ${ }^{8}$.

De acuerdo con lo previsto por el art. 57 LRJS si no fuese posible cumplir con el acto de comunicación mediante correo certificado, la entrega de copia de la resolución o de cédula al destinatario será la segunda de las formas a seguir, lo que lógicamente, supone la necesidad de que el correspondiente funcionario se persone en el domicilio del destinatario de la comunicación entregando allí la cédula al propio interesado, si lo encontrare, o, en su defecto, a los parientes, empleados o vecinos a los que el propio precepto alude. De este modo, se especifica legalmente que la cédula se entregará en principio al destinatario y si ello no fuera posible al pariente más cercano o familiar o empleado, siempre que sean mayores de catorce años; o, al portero o conserje de la finca.

\footnotetext{
${ }^{7}$ Entre otras, STSJ de Cataluña de 16 de julio de 2002, Rec. 9122/01; STSJ de Murcia de 27 de octubre de 2003, Rec. 1064/03; STSJ de Asturias de 20 de febrero de 2004, Rec. 722/03.

${ }^{8}$ En este sentido, entre otras muchas, STSJ de Andalucía de 22 de enero de 2008, Rec. 1333/07; STSJ de Murcia de 4 de diciembre de 2006, Rec. 1101/06; o, STSJ de Castilla y León de 20 de marzo de 2006, Rec. 119/06.
} 
Finalmente, de acuerdo con lo previsto en el art. 59.1 LRJS, en caso de que no se conociese el paradero del interesado, habiéndose agotado todos los medios para ello, se utilizará, como vía de comunicación la edictal que, según ha señalado la STC 47/2019, de 8 de abril, resulta una "modalidad de carácter residual y de eficacia harto limitada". Ha de destacarse que el requisito básico a cumplir para proceder a la comunicación por edictos es el del agotamiento de todos los medios que el Tribunal tiene a su alcance para conocer el domicilio del destinatario. Y lo cierto es que el cumplimiento de esta condición se interpreta de modo muy estricto por los Tribunales. Así pues, no cabe duda de que el emplazamiento edictal constituye "un remedio último para los actos de comunicación procesal, de carácter supletorio y excepcional, que requiere el agotamiento previo de los medios de comunicación ordinarios, que ofrecen mayores garantías y seguridad de recepción para el destinatario, y la convicción —obtenida con criterios de razonabilidad - del órgano judicial que ordene su utilización de que, al ser desconocido el domicilio o ignorado el paradero del interesado, resultan inviables o inútiles los otros medios de comunicación procesal" (SSTC 106/2006, de 3 de abril, 126/2006, de 24 de abril, 306/2006, de 23 de octubre).

En fin, es importante para acabar hacer referencia a que la aportación por parte del demandante del domicilio o domicilios conocidos del demandado que impone el art. 155 LEC, puede ser una arma de doble filo, esto es, puede llevar a una actuación del mismo consistente en la maquinación fraudulenta regulada por el art. 510.4 LEC, contraria al principio de buena fe procesal que exige la diligencia mínima destinada a suministrar al órgano jurisdiccional el conocimiento del domicilio del demandado y evitar así la indefensión que pueda producir la citación por edictos. Por lo tanto, deberemos estar a las circunstancias probadas a fin de detectar posibles supuestos de maquinación fraudulenta, teniendo en cuenta para su apreciación su necesario carácter intencional ${ }^{9}$.

\footnotetext{
${ }^{9}$ Se entiende que concurre maquinación fraudulenta cuando se aprecia "negligencia inexcusable en la ocultación por el demandante del domicilio real del demandado" (SSTS de 24 de octubre de 2007, Rec. 22/2006; y, de 22 de abril de 2009, Rec. 19/2008); "pasividad maliciosa por parte del demandado" (STS de 6 de noviembre de 1992, Rec. 967/1990); "la consciente indicación de un domicilio respecto de la demandada distinto del real" (STS de 31 de diciembre de 1998, Rec. 4435/1996); "la designación del centro de trabajo, conociendo que estaba cerrado y la empresa sin actividad o de un domicilio cerrado en que no es posible la citación cuando otros trabajadores de la empresa en igual situación señalan el real donde si puede ser citada la empresa" (STS de 19 de julio de 1996, Rec. 907/1995). Ahora bien, también es posible que de no concurrir el factor intencional, determinante en la maquinación fraudulenta, esta conducta no pueda imputarse al demandante. En este sentido, existe en la actualidad una corriente jurisprudencial que con claridad exige que concurra un componente intencional para producir la situación de indefensión (SSTS de 5 de mayo de 2005, Rec. 26/2004; de 10 de octubre de 2005, Rec. 43/2004; 31 de enero de 2006, Rec. 44/2004; y, de 5 de diciembre de 2006 Rec. 28/2005). Así, se afirma que esta conducta, no concurre, por ejemplo, cuando "la demandante ofrece varios domicilios y luego sólo es citado en uno de ellos por el Juzgado" (STS de 13 de abril de 2005 Rec. 12/2003); "si los demandantes ofrecen el domicilio del centro de trabajo de la empresa cuando esta ha desaparecido sin dejar constancia de ningún otro" (STS de 18 de septiembre de 2000, Rec. 671/2000); "cuando el cambio de domicilio es desconocido para el trabajador" (STS de 14 de febrero de 2002 Rec. 2765/2000); "si el demandado no comparece a pesar de ser citado en la persona de terceros en su auténtico domicilio" (STS de 9 de mayo de 2003 Rec. 29/2002); "cuando la actora ofrece el único domicilio que conoce aunque la empresa resulta que está cerrada" (STS de 29 de octubre de 2004 Rec. 27/2003); "cuando la comunicación se hace en el domicilio fijado en el contrato, en las hojas salariales y en la comunicación de la extinción contractual y que se mantuvo en el Registro
} 


\section{El primer emplazamiento o citación del demandado}

Dentro del estudio del lugar de los actos de comunicación, debemos detenernos finalmente en la excepción reseñada anteriormente en relación con el primer emplazamiento o citación del demandado, dado que esta es una cuestión que se ha planteado como ciertamente "problemática"10. El régimen jurídico específicamente aplicable viene establecido en los apartados 1, 2 y 3 del art. 155 LEC y se limita expresamente a la comunicación por remisión al domicilio de los litigantes. Por otra parte, en el segundo párrafo del apartado cuatro del art. 273 LEC se prevé un supuesto en el que, aun habiéndose presentado por vía telemática o electrónica los escritos y documentos, también resulta obligatoria su presentación en soporte de papel. Este precepto viene a señalar que los escritos y documentos presentados por vía telemática o electrónica indicarán el tipo y número de expediente y año al que se refieren e irán debidamente foliados mediante un índice electrónico que permita su debida localización y consulta. La presentación se realizará empleando firma electrónica reconocida y se adaptará a lo establecido en la Ley 18/2011. Únicamente de los escritos y documentos que se presenten vía telemática o electrónica que den lugar al primer emplazamiento, citación o requerimiento del demandado o ejecutado, se deberá aportar en soporte papel, en los tres días siguientes, con tantas copias literales cuantas sean las otras partes.

Nos encontramos pues ante un "régimen jurídico sui generis respecto de la primera citación o emplazamiento del demandado", tal y como lo ha considerado la STC 47/2019, de 8 de abril. Y es que, teniendo en cuenta lo dispuesto por el art. 155.1.2 LEC, la aplicación de los arts. 53.1 y 55 LRJS en materia de notificación del primer emplazamiento impone la obligación de que la comunicación se realice por remisión al domicilio. En este sentido, la citada sentencia, que ha sido pionera en analizar este tipo de situaciones y que pone de manifiesto las carencias de una regulación "tomada a salto de mata de otra ajena al ámbito procesal"11 , ha sido clara a la hora de interpretar como un error la atribución "a lo dispuesto en los arts. 53.1 y 55 LRJS de la facultad de efectuar los actos de comunicación a través de medios electrónicos, telemáticos o de otra clase semejante, como modo alternativo a la utilización del correo certificado con acuse de recibo en el domicilio señalado".

En consecuencia, en el supuesto planteado ante el TC, el hecho de que la parte afectada no hubiera accedido a la notificación en el plazo señalado en el art. 162.2 LEC, "no puede ser considerado un factor determinante de la falta de celo o del comportamiento omiso que se alega, ni capaz, por ende, de enervar la indefensión de la que se queja la recurrente". En contra de este planteamiento se ha entendido que si el interesado tiene una dirección electrónica habilitada y retira o deja pasar incluso los plazos para abrir el

Mercantil" (STS de 25 de mayo de 2009, Rec. 10/2008); o, cuando "se aporta en el escrito de demanda un domicilio que figuraba en las dos cartas de despido que recibió" (STS de 13 de abril de 2005, Rec. 12/2003).

${ }^{10}$ En este sentido, TORRÓ ENGUIX, J., "Aspectos críticos del proceso laboral y el expediente judicial electrónico", Revista de Derecho Social y Empresa, n 9, septiembre, 2018, p. 14.

${ }^{11}$ BARRIO CALLE, M.A., “Algunas distorsiones en los actos de comunicación telemáticos...”, op. cit., p. 81. 
buzón, deberíamos tenerle por notificado, aunque sea la primera citación para que comparezca en los actos de conciliación, y en su caso, juicio ${ }^{12}$. Es más, se ha considerado que, aun entendiendo en este caso que la comunicación electrónica no se ajusta a derecho, puede no acaecer la vulneración del derecho de tutela judicial efectiva si no se constata la indefensión material de la parte demandada ${ }^{13}$.

No obstante, para el Alto Tribunal, en interpretación que comparto, es esencial, desde el punto de vista del derecho a la tutela judicial efectiva, sostener la interpretación señalada, dado que, de lo contrario, la obligación de cumplir con los requisitos exigidos por las normas procesales en relación con los actos de comunicación referidas al primer emplazamiento no sería tal, puesto que siempre podría achacarse a la parte su falta de diligencia en el acceso a la comunicación electrónica.

En conclusión, tal y como se afirma en la STC 7/2020, de 27 de enero, la obligación general de que sea la electrónica la fórmula de comunicación ordinaria no autoriza a entender que los sujetos obligados queden constreñidos, en cualquier caso y circunstancia, a recibir los actos de comunicación a través de esos medios, hasta el extremo de quedar neutralizada la regulación legal especialmente prevista, sin distinción de supuestos o sujetos, para las primeras citaciones o emplazamientos del demandado ${ }^{14}$.

\section{La forma de presentación de los escritos y documentos}

El art. 44.2 LRJS traslada expresamente al orden social la referencia del art. 135 LEC sobre la presentación de escritos y documentos por medios técnicos, siempre y cuando tanto las partes como la propia Oficina cuenten con esos medios para el envío y recepción y quede garantizada la autenticidad de la comunicación, quedando constancia de la remisión y recepción y de la fecha en que se presenten, con el resguardo acreditativo de su presentación que proceda. A esta posibilidad también se refiere el art. 230.4 LOPJ que expresamente reconoce a las partes que pretendan obtener la tutela judicial efectiva el uso de estos medios técnicos si bien cumpliendo con los requisitos precisos para que no se vean alteradas en ningún momento las garantías del procedimiento.

Como hemos visto antes, la aprobación y entrada en vigor de las normas reguladoras del uso de las tecnologías de la información en la Administración de Justicia ha supuesto una

\footnotetext{
12 Ibídem, p. 76.

${ }^{13}$ En este sentido, DE LAMO RUBIO, J., "Citación telemática a juicio y nulidad de actuaciones judiciales en el orden social”. Diario La Ley, No 9181, Sección Tribuna, abril, 2018, p. 2.

${ }^{14}$ Tan es así que, señala la STC 7/2020, por su vinculación a los poderes públicos tras la publicación en el "BOE" de la STC 47/2019 [arts. 40.2 LOTC y 5.1 LOPJ], la Secretaría General de la Administración de Justicia del Ministerio de Justicia ha dirigido una comunicación el 21 de mayo de 2019 a las secretarías de gobierno del Tribunal Supremo, Audiencia Nacional y Tribunales Superiores de Justicia de las Comunidades Autónomas, citando la STC 47/2019, en su fundamento jurídico 4, para que cuiden "que la doctrina interpretativa de las normas procesales reguladoras del primer emplazamiento de personas jurídicas sentada por el Tribunal Constitucional, cuyo obligado acatamiento impone la Ley Orgánica del Poder Judicial, sea observada en todas las oficinas judiciales del territorio".
} 
transformación del sistema de presentación de escritos. La Ley 18/2011, dedica el Capítulo IV del Título IV a la regulación de la tramitación electrónica. Y en su art. 38 viene a señalar que la presentación de toda clase de escritos, documentos, dictámenes, informes u otros medios o instrumentos se ajustará a lo dispuesto en las leyes procesales, debiendo ir acompañados en todo caso del formulario normalizado a que se refiere el apartado 4 del art. 36, en el que además se consignará el tipo y número de expediente y año al que se refiera el escrito. En todo caso, la presentación de escritos, documentos y otros medios o instrumentos se ajustará a las siguientes reglas:

a) Los documentos en papel que, conforme a lo dispuesto en las leyes procesales puedan o deban ser aportados por las partes en cualquier momento del procedimiento, deberán ser incorporados como anexo al documento principal mediante imagen digitalizada de la copia, si fueran públicos, o del original del documento obrante en papel, si se tratara de documentos privados. El archivo de la imagen digitalizada habrá de ir firmado mediante la utilización de los sistemas de firma electrónica previstos en la presente Ley, en las leyes procesales o en otras normas de desarrollo.

b) Los documentos electrónicos públicos o privados se incorporarán como anexo al documento principal siguiendo los sistemas previstos en esta Ley o en sus normas de desarrollo y conforme a lo previsto en la Ley 59/2003, de 19 de diciembre, de firma electrónica.

c) En caso de que fueran impugnados por la parte contraria, se procederá conforme a lo dispuesto en las leyes procesales y, en su caso, en la Ley 59/2003, de 19 de diciembre, de firma electrónica.

d) No se admitirá la aportación en otra forma, salvo en el supuesto de que, por las singularidades características del documento, el sistema no permita su incorporación como anexo para su envío por vía telemática. En estos casos, el usuario hará llegar dicha documentación al destinatario por otros medios en la forma que establezcan las normas procesales, y deberá hacer referencia a los datos identificativos del envío telemático al que no pudo ser adjuntada, presentando el original ante el órgano judicial en el día siguiente hábil a aquel en que se hubiera efectuado el envío telemático. Tales documentos serán depositados y custodiados por quien corresponda en el archivo, de gestión o definitivo, de la oficina judicial, dejando constancia en el expediente judicial electrónico de su existencia únicamente en formato papel.

Cuando se deban incorporar documentos sobre los cuales existan sospechas de falsedad, deberá aportarse en todo caso además el documento original, al que se le dará el tratamiento contemplado en el párrafo anterior.

e) En los casos en que se deban aportar al procedimiento medios o instrumentos de prueba que por su propia naturaleza no sean susceptibles de digitalización, serán depositados y custodiados por quien corresponda en el archivo de gestión o definitivo de 
la oficina judicial, dejando constancia en el expediente judicial electrónico de su existencia.

La aplicación de este precepto y, en general, la puesta en marcha de la presentación de los escritos a través del sistema LexNet, ha llevado al TS a introducir diferentes matizaciones en el entendido de que la novedad del sistema telemático utilizado y los innumerables interrogantes que se abren tanto a profesionales como a los tribunales con respecto a cualquier incidencia de LexNet, imponen, en particular a los órganos judiciales como garantes del derecho a la tutela judicial efectiva, un especial cuidado en la adopción de decisiones que afecten a esa materia. De este modo, señala el TS, "no se puede obviar que el sistema está dando sus primeros pasos, exigiendo de todos los sujetos implicados en su utilización un especial esfuerzo de adaptación al mismo; a lo anterior se añade que la puesta en marcha del sistema está poniendo en evidencia diversas incidencias y disfunciones susceptibles de corrección; y todo ello sin olvidar otro dato no de menor importancia para los profesionales, en particular abogados y procuradores, cual es, que los modelos de utilización del sistema no son únicos, sino que los mismos pueden variar en atención a la Comunidad Autónoma en la que se halle la sede del órgano jurisdiccional al que se dirige el escrito" (ATS de 4 de octubre de 2017, Rec. 7/2017).

No obstante, el proceso de adaptación no puede extenderse en el tiempo sine die. Y ello ha llevado al TS a considerar que, dado que se ha seguido un proceso transitorio de adaptación, tras el mismo se debe entender que las condiciones de uso de la plataforma LexNet han de ser conocidas por los operadores jurídicos. Estos deben dotarse de una formación al efecto y, aunque es cierto que "el derecho de acceso al recurso puede resultar menoscabado si se impide el acceso a las instancias supraordenadas con obstáculos indebidos o por denegación injustificada, no explicada o debida a un error imputable al órgano judicial (sentencias del Tribunal Constitucional 130/1987 , 28/1994 y 162/1995 )", ha de asumirse también que está excluida del ámbito protector del art. $24 \mathrm{CE}$ "la indefensión debida a la pasividad, desinterés, negligencia, error técnico o impericia de la parte o de los profesionales que representen o defiendan a las partes (por todas, sentencias del Tribunal Constitucional 109/2002 , 141/2005, o 160/2009)" (ATS de 1 de marzo de 2018, Rec. 83/2017).

En este sentido, podemos reseñar algunos ejemplos de la interpretación que la Sala Cuarta está haciendo respecto de la presentación de escritos por LexNet en relación con diferentes incidencias que se han presentado con el uso de esta plataforma:

- En primer lugar, en lo que respecta a la firma de los documentos presentados por LexNet, la normativa de aplicación deja claro que cuando un abogado presenta un escrito ante un órgano jurisdiccional vía LexNet, ya sea usando la plataforma del Ministerio de Justicia, ya la del Colegio de Abogados correspondiente, está, de forma automática, firmándolo electrónicamente, y no otra cosa se desprende del propio manual elaborado en el Ministerio y colgado en su web para la ayuda de uso del sistema a los profesionales, 
que inevitablemente genera una confianza legítima de los letrados [...]" (ATS de 29 de noviembre de 2016, Rec. 37/2016 ${ }^{15}$ ).

- En segundo lugar, por lo que se refiere a la problemática del rechazo del recurso presentado vía LexNet por incorrecta cumplimentación del formulario electrónico y su repercusión en el cómputo de los plazos, se considera que cuando consta claramente en el resguardo acreditativo que el motivo justificativo del rechazo fue la incorrecta denominación del procedimiento de destino, "no estamos ante un rechazo causado por una razón técnica atinente a la plataforma mencionada". Por ello, no puede incardinarse esta incidencia como una causa técnica a los efectos del art.135.2 LEC, que habilita para la presentación del escrito en la oficina judicial el primer día hábil siguiente acompañando el justificante de dicha interrupción; contemplada igualmente en el art. 12 RD 1065/2015 (ATS de 21 de mayo de 2019, Rec. 13/18). No obstante, en relación con esta interpretación se advierte que, si se constata la existencia de esas anomalías técnicas de LexNet, la parte afectada deberá, de acuerdo con lo previsto en el art. 135.2 LEC, presentar el escrito en la oficina judicial el día siguiente hábil acompañando al mismo la justificación de la citada anomalía (ATS de 18 de octubre de 2017, Rec. 39/2017).

Partiendo pues de la combinación de esta regla general sobre la inexistencia de error técnico en los casos de incorrección en el formulario y su excepción cuando el error técnico se acredita debidamente, las soluciones adoptadas por el TS no han sido unívocas, dependiendo precisamente de las concretas circunstancias de los supuestos analizados, entendiéndose que:

- La presentación por LexNet del escrito de preparación sin constar el número del recurso de suplicación es un error que debe ser subsanado a través de nuevos intentos en la citada plataforma, lo que impide considerar la actuación del letrado de pasiva, desinteresada, negligente o falta de pericia (por todos, ATS de 21 de mayo de 2019, Rec. 13/2018), por lo que si estos nuevos intentos no se acreditan sí cabe apreciar la falta de diligencia del letrado (ATS de 1 de marzo de 2018 Rec. 83/2017).

- El error procesal en la remisión vía LexNet del recurso de casación para la unificación de doctrina a la Sala Cuarta del TS en lugar de la Sala de lo Social del TSJ correspondiente no puede considerase en ningún caso subsanable: "Es reiterada la doctrina en relación con la presentación de documentos en órganos judiciales inadecuados, sin que la presentación vía LexNet altere el criterio hasta ahora mantenido. Así los autos de la sala de 24 de septiembre de 2012 (R. 51/2012), 11 de junio de 2012

\footnotetext{
${ }^{15}$ Indica el TS, que "el envío por LexNet conlleva la firma electrónica por el profesional de forma indisoluble (art. 6.4, 9.3, 13.1, 14.e) y 17.2 RD 1065/15). En particular, puede destacarse que el art 13.1 señala que "el sistema LexNet garantiza el contenido íntegro de las comunicaciones y la identificación del remitente", mientras el art. 14, al establecer las funcionalidades del sistema, destaca que una de ellas es "la constancia de un asiento por cada transacción con los siguientes datos (...) identidad del remitente y del destinatario...". Por su parte el art. 17. 2 señala que "Los usuarios del sistema presentarán sus escritos utilizando firma electrónica cualificada. Los documentos electrónicos anexos también serán firmados electrónicamente mediante certificado electrónico reconocido o cualificado".
} 
(R. 25/2012), 11 de octubre de 2012 (R. 74/2012) y 18 de diciembre de 2012 (R. 84/12) desestiman recursos de queja en supuestos, como el presente, de presentación del escrito formalizando el recurso de casación ante el Tribunal Supremo y no ante la sala de Suplicación. No resulta de aplicación, por tanto, la solución alcanzada en los autos de esta Sala citados en la interposición del recurso de queja, pues en ellos se abordan cuestiones relativas a errores en la formalización del formulario informático -a la hora de indicar el procedimiento de destino o si se correspondía con el inicio de un nuevo procedimiento o la continuación del ya iniciado-; errores que no resultan comparables con la remisión del escrito vía LexNet a un órgano judicial inadecuado" (ATS de 22 de mayo de 2019, Rec. 3/2019; en el mismo sentido, referido al recurso de casación ordinaria presentado ante el TS en lugar de ante la AN, ATS de 7 de mayo de 2019, Rec. 55/2018).

- El rechazo por incorrecta cumplimentación del formulario electrónico sin que el sistema LexNet dé alerta alguna no puede elevarse a la categoría de defecto procesal insubsanable, sino que este error es un defecto procesal eminentemente subsanable (AATS de 4 de octubre de 2017, Rec. 7/2017; y, de 19 de junio de 2018, Rec. 90/2017).

- El error en la selección de un campo del formulario, cuando se acompaña el documento objeto de catalogación, "no tiene naturaleza de formalidad esencial constitutiva y solemne del rellenado correcto de este apartado, como forma constitutiva ad solemnitatem, sino que es más adecuado caracterizar este requisito formal como forma ad probationem (en realidad para su tramitación y curso por vía informática LexNet) y más difícil aun es negar su naturaleza de trámite esencialmente subsanable" (ATS de 4 de julio de 2019, Rec. 16/2019).

A través de todos los Autos reseñados podemos deducir que la doctrina del TS responde a la que se ha considerado la "declaración de principios" del TC en esta materia ${ }^{16}$, esto es, la referencia que en la STC 55/2019, de 6 de mayo encontramos a que: "La modernización de la administración de justicia mediante la generalización en el uso de las nuevas tecnologías y, en lo que aquí nos atañe, a través de las comunicaciones electrónicas procesales, no constituye un fin en sí mismo sino un instrumento para facilitar el trabajo tanto del órgano judicial, como de los justiciables que actúan en los procesos a través de los profesionales designados o directamente por ellos cuando esto último es posible. No pueden en ningún caso erigirse tales medios tecnológicos, en impedimento o valladar para la obtención de la tutela judicial a la que «todas las personas» (art. 24.1 CE) tienen derecho".

En efecto, la doctrina del TS en esta materia se construye sobre este planteamiento del TC que parte del carácter instrumental de las nuevas tecnologías, que son un recurso esencial pero no pueden transformarse en ningún caso en un obstáculo para que los órganos jurisdiccionales impartan justicia. En este sentido, el TC también se ha pronunciado sobre la proyección de su doctrina a las comunicaciones electrónicas en la

${ }^{16}$ MARTÍNEZ MOYA, J., "Las comunicaciones electrónicas procesales...”, op. cit., p. 8. 
administración de justicia. Así, por ir a ejemplos concretos, podemos señalar que se ha entendido que el error relacionado exclusivamente con el código específico de la aplicación LexNet no puede considerarse un error esencial cuando el procedimiento transcrito en el formulario era correcto y también lo era el órgano judicial de destino. En este sentido, la STC 55/2019, de 6 de mayo, a la que nos referíamos antes, entiende que la necesidad de completar ese código es un requisito formal de carácter accesorio, dado que se trata de una exigencia que ha sido directamente introducida por los técnicos al programar el contenido del formulario del sistema LexNet. En consecuencia, aplicando el criterio de que la tecnología no puede ser un obstáculo para la justicia, la conclusión del TC no puede ser otra, en el entendido de que el error en lo accesorio de la tecnología de las comunicaciones debe ser controlado por el órgano judicial.

Por lo que se refiere al tratamiento de los errores cometidos en el envío de escritos por las partes, es significativa la STC 6/2019, de 17 de enero, que, en relación con el sistema de comunicaciones procesales electrónicas detalló:

- Que el sistema LexNet está dotado de las garantías de autenticidad y constancia fehaciente del envío y recepción de los actos de comunicación, estando operativo para los órganos judiciales radicados en el ámbito territorial del Ministerio de Justicia y en aquellas comunidades autónomas que tienen suscrito convenios con ese Ministerio (art. 10 del Real Decreto 1065/2015) para la utilización del indicado sistema.

- Que tales garantías operan también en las demás plataformas habilitadas para las comunicaciones electrónicas, sean del Estado o de las comunidades autónomas (art. 11 RD 1065/2015), en cuanto todas sirven a los mismos fines.

- Que, entre esas garantías, se encuentra, la relativa al modo de acreditar la presentación de los escritos procesales, conforme al art. 17.3 del RD 1065/2015, que ordena la emisión de un resguardo electrónico tanto del envío, como de la disposición y recepción del mismo por el destinatario.

- Que cuando se detecten anomalías en la transmisión o no se haya podido completar el envío, el art. 17.5 del mismo RD dispone que se emita el correspondiente mensaje de error para que proceda a la subsanación o realice el envío en otro momento o utilizando otros medios.

- Que también en relación con las deficiencias del canal de comunicación electrónico, disponen los arts. 135.2 LEC y 30.4 de la Ley 18/2011, que se garantice la debida información a los usuarios sobre las interrupciones del servicio, sean estas o no planificadas, posibilitando en el segundo caso que el remitente pueda consignar el escrito 
en la oficina judicial el primer día hábil siguiente, presentando el justificante de la interrupción ${ }^{17}$.

En esta importante sentencia el TC se pronunció sobre la cuestión de constitucionalidad presentada respecto del último párrafo del art. 152.2 LEC y la posible vulneración del derecho a la tutela judicial efectiva. Y, de manera expresa, se puntualiza en la misma que, de acuerdo con el art. 149 LEC los actos de comunicación son seis: notificaciones, emplazamientos, citaciones, requerimientos, mandamientos y oficios. Y, por su lado, la LRJS se refiere a las "citaciones, notificaciones, emplazamientos y requerimientos" (arts. 55) o solamente a los tres primeros tipos de actos (arts. 56.1; 60.1; 61).

Pues bien, respecto del último inciso del art. 152.2 LEC en relación con el "aviso" sobre la puesta a disposición de un acto de comunicación, la STC 6/2019 aclara que no nos encontramos ante un acto de comunicación, sino solo ante una información que se provee acerca de la puesta a su disposición de un acto de comunicación. Y, "en coherencia con este limitado fin, el inciso primero de dicho párrafo ya advierte que aquel aviso no sirve para la práctica de notificaciones; y que la validez del acto de comunicación no debe presumirse del mero cumplimiento de la obligación de enviar el aviso". Por ello, "con independencia de la forma en que se realice el acto de comunicación, la oficina judicial enviará el referido aviso". En este sentido, el TC entiende que "el aviso representa un acto procesal efectuado por la oficina judicial, de carácter accesorio, que ayuda o facilita el conocimiento del hecho de haberse practicado un acto de comunicación, pero a cuyo acceso efectivo el aviso no coadyuva, sino que exige la utilización del canal electrónico habilitado para el profesional. El inciso final del precepto cuestionado, que separa entonces los efectos jurídicos de la omisión del aviso, respecto de la validez del acto de comunicación, aparece por ello como una medida estrictamente necesaria para asegurar la propia eficacia del sistema de justicia electrónica en su configuración actual”. En consecuencia, debe considerarse que:

a) El acto de comunicación queda desvinculado del aviso de puesta a disposición de dicho acto - ni el aviso sirve para la práctica de notificaciones ni el acto de comunicación debe presumirse válido por el mero cumplimiento de la obligación de enviar el aviso-.

b) El contenido del aviso no viene regulado ni en la LEC ni en la normativa sobre comunicaciones electrónicas en el ámbito de la Administración de Justicia, por lo que el aviso no goza de la protección de las garantías propias del sistema Lexnet o de la sede

\footnotetext{
${ }^{17}$ En atención a este mandato, el Ministerio de Justicia dispone de un enlace para consulta pública, con la relación de las distintas incidencias por interrupción del servicio registradas en la plataforma de LexNet desde diciembre de 2015, tanto aquellas previamente programadas ("intervenciones") como las no programadas ("anomalías"), pudiendo el interesado descargarse el justificante que le interese. Por último, los arts. 135 y 162 LEC contemplan soluciones para el caso en que el sistema no soporte la carga de determinados documentos anexos, y los mismos deban presentarse en papel el día hábil siguiente.
} 
judicial electrónica relativas a la autenticidad y al registro de todas las fases de la operación virtual -envío, recepción y lectura-.

c) Se deja a la libre voluntad del sujeto destinatario la selección del dispositivo y la opción misma de recibir el aviso, dado que este no es ni preceptivo ni de alcance general para todos, lo que no sucede con la transmisión de los propios actos de comunicación a través de LexNet.

d) La doctrina constitucional sobre el derecho a no padecer indefensión ha sido dictada a propósito de los actos de comunicación, y el aviso del art. 152.2 párrafo tercero LEC no lo es, por lo que dicha doctrina no le resulta aplicable.

e) Los profesionales de la justicia tienen la obligación de consultar el buzón LexNet con la asiduidad que exija el número y naturaleza de los asuntos judiciales que tienen a su cargo. Y, del mismo modo, es obligatorio para el particular que actúa sin postulación y hace uso de los canales electrónicos habilitados, la consulta del expediente digital.

f) La falta de vinculación entre el aviso y los actos de notificación en la LEC y en la normativa sobre comunicaciones electrónicas en el ámbito de la Justicia impiden que pueda reclamarse una transgresión del art. 24 CE en relación con el principio de confianza legítima respecto de los plazos procesales.

\section{El tiempo para la realización de los actos de comunicación}

El plazo para la notificación a todos los sujetos que sean parte en el juicio de las resoluciones procesales será el del mismo día de su fecha, o de la publicación en su caso, y no siendo posible, en el día hábil siguiente (art. 54.1 LRJS). No cabe duda de que la notificación en plazo también tiene como fundamento el cumplimiento del derecho fundamental a la tutela judicial efectiva (art. $24 \mathrm{CE}$ ), ya que para que este derecho se haga efectivo es necesario que los interesados tengan noticia de la existencia del proceso y de las distintas situaciones que en el mismo se van produciendo.

En todo caso, esta regla general sobre los plazos de notificación tiene dos importantes excepciones: de un lado, la referida al plazo para la notificación de sentencias (dos días desde la publicación — art. 97.1 LRJS—); y, de otro, la que contempla el propio art. 54.3 LRJS en relación con la necesidad de que hubieran de adoptarse por el Juez o la Sala medidas tendentes a garantizar los derechos que pudieran corresponder a las partes o a asegurar la efectividad de la resolución judicial, y la notificación inmediata al afectado de las actuaciones procesales o de la medida cautelar, preventiva o ejecutiva adoptada pudiera poner en peligro su efectividad. En este supuesto, el órgano judicial podrá, motivadamente, acordar la demora en la práctica de la notificación durante el tiempo indispensable para lograr dicha efectividad. En relación con ello, se ha señalado que no 
parece que se trate en estos casos de que el órgano judicial haya de dictar dos resoluciones, sino que se trata de que en una única resolución se decida tanto la adopción de las medidas aseguradoras como la demora de la comunicación ${ }^{18}$.

Pues bien, respecto del tiempo para la comunicación también hemos de señalar que la transformación tecnológica en las comunicaciones que estamos analizando a lo largo de todo el trabajo ha sido tenida en cuenta por la Sala Cuarta del TS. En materia de plazos procesales de hecho el 6 de julio de 2016 esta Sala aprobó el Acuerdo no jurisdiccional del Pleno de la Sala de lo Social del Tribunal Supremo sobre notificaciones a través del sistema Lexnet en el orden social y plazos procesales. De hecho, el TS ha considerado que el sistema de notificaciones, es un ámbito especialmente sensible del proceso porque de su claridad y seguridad depende, en buena medida, "la correcta evolución del procedimiento y su avance en un entorno adecuado de seguridad jurídica que se desarrolla en dos direcciones: La primera dirigida a facilitar al órgano judicial la constancia del cumplimiento por las partes y por el propio órgano de los requisitos y fases procesales, como garantía última del resto de los principios procesales; y la segunda dirigida a garantizar a las partes el conocimiento puntual y adecuado de las resoluciones y de sus posibilidades de actuación procesal, en aquel entorno de seguridad jurídica y como garantía última del derecho fundamental a la tutela judicial efectiva" (ATS de 29 de noviembre de 2016, Rec. 28/16).

De acuerdo con la motivación del mencionado Acuerdo no jurisdiccional, el TS considera que la implantación del sistema de comunicaciones a través de las nuevas tecnologías viene obligando a modificar y adaptar las tradicionales previsiones de las leyes procesales. Por estricta referencia al orden social debe recordarse el tenor de lo previsto en los artículos 56.5 y 60.3 párrafo segundo LRJS. También entran en juego, sea de forma supletoria, sea por remisión, las prescripciones de la Ley de Enjuiciamiento Civil, en particular sus artículos 162.2 y 135.5. Y, finalmente, resultan aplicables los arts. 8 y 33.2, junto con la DA $7^{a}$ Ley 18/2011, desarrollados por el RD 1065/2015. Con base en estos preceptos, el Acuerdo distingue entre:

-Notificaciones a través del servicio de los colegios de procuradores: Cuando un acto o resolución judicial se notifique por el Juzgado o Tribunal a través del servicio organizado por los Colegios de Procuradores, se aplicará el régimen procesal común propio de estas notificaciones. En consecuencia, se tendrán por notificados al día siguiente a la fecha de su recepción.

- Notificaciones a través de:

A) Cuando haya constancia de la correcta remisión del acto de comunicación y transcurran tres días hábiles sin que el destinatario acceda a su contenido, se entenderá que la comunicación ha sido efectuada con plenos efectos procesales. En este caso los

\footnotetext{
${ }^{18}$ MONTOYA MELGAR, A., y otros, Comentarios a la Ley de Procedimiento Laboral, Navarra, Aranzadi, 2003, p. 184.
} 
plazos para desarrollar actuaciones impugnatorias comenzarán a computarse desde los días siguientes al tercero, todos ellos hábiles.

B) Si se accede al contenido el día de su remisión o durante los tres días hábiles posteriores, la notificación se entiende realizada al día siguiente de dicho acceso. De este modo, si se accede el día tercero, la notificación se entiende realizada el cuarto día hábil y los plazos comienzan a computar desde el quinto.

- Presentación de escritos a término: lo dispuesto en el art. 135.5 LEC, sobre posibilidad de presentar escritos hasta las quince horas del día hábil siguiente al vencimiento de un plazo, resulta aplicable respecto de los nuevos sistemas de recepción de escritos en el orden jurisdiccional social.

En aplicación de este Acuerdo, el TS ha venido a interpretar que el art. 60.3 LRJS manifiesta que las notificaciones a las partes, se tendrán por realizados el día siguiente a la fecha de recepción que conste en la diligencia o en el resguardo acreditativo de su recepción cuando el acto de comunicación se haya efectuado por los medios y con los requisitos que establece el apartado 1 del art. 162 LEC porque este último precepto distingue permanentemente dos momentos (ATS de 8 de mayo de 2018, Rec. 44/17):

- El de enviar y recibir

- El de la constancia de la remisión y de la recepción

$\mathrm{Y}$ es en el "contexto de la diferencia existente entre los dos momentos", en la que se inserta la regulación del apartado 2 del art. 162, en la que, constando la correcta remisión del acto de comunicación, transcurrieran tres días sin que el destinatario accediera a su contenido, y por tanto no se hubiera producido aquella necesaria recepción a la que se refiere el art. 60.2 LRJS. Por tanto, la previsión de los artículos 60.2 LRJS y 162.2 LEC, lejos de contener previsiones incompatibles, vienen a complementarse:

- El primero detalla cuándo se considera efectuado el acto de comunicación: al día siguiente de la fecha de recepción

-El segundo determina cuándo se considera efectuado el acto de comunicación en los casos en los que aquella recepción no tiene lugar

En este sentido, considera el TS que el principio de celeridad que preside el proceso laboral no se ve tampoco comprometido por la aplicación del art. 162.2 LEC, sino más bien al contrario, "porque dicho precepto no hace sino traer a la norma procesal general el efecto tradicional de la inactividad procesal, formulado en dos clases, el general de exclusión de la posibilidad de realizar el acto omitido (efecto preclusivo) y los efectos especiales, que determina la ley para cada caso concreto, y principalmente el de la ficción de que el acto omitido se ha realizado, cuando su ejecución sea necesaria para la continuación del proceso, supliendo la realidad por la ficción. Esto es precisamente lo que dispone el art. 162.2 de la Ley de Enjuiciamiento Civil, considerando efectuada 
legalmente una comunicación a pesar de que el destinatario no haya accedido a su contenido, habiendo podido hacerlo, desplegando a partir de ese momento los efectos procesales de la notificación recibida".

En este sentido, se ha de considerar que no cabe admitir una interpretación de la ley o de los preceptos procesales que limite "incomprensiblemente su potencialidad, generando una disfunción interpretativa entre las distintas jurisdicciones, que carece de sentido [...]. No considerar aplicable tal precepto en la jurisdicción social por incompatible con el art. 60.3 de la Ley Reguladora de la Jurisdicción Social, supone instalar en nuestra jurisdicción la permanente ficción de tener por recibida una comunicación y por hecha efectivamente la notificación, desde el momento en que esta ha sido enviada, cuando la tecnología permite conocer, distinguir y dejar constancia, tanto del envío como de la recepción y acceso al contenido de la comunicación, permitiendo a partir de ello que los correspondientes efectos procesales se adapten perfectamente a cada una de esas circunstancias" (ATS de 6 de febrero de 2019, Rec. 49/18).

Partiendo pues de estos principios interpretativos generales en materia de plazos a la hora de abordar las incidencias del sistema LexNet se ha entendido, por ejemplo, que:

a) La mera manifestación de no haber recibido la comunicación, sin ningún tipo de prueba, justificación o documento que la avale y que permita desvirtuar la constancia de la notificación en el sistema de gestión procesal a través de LexNet, no resulta en modo alguno suficiente para estimar el recurso de queja y evitar la confirmación de la resolución por la que se acuerda, conforme dispone el artículo 223.3 LRJS, poner fin al trámite del recurso de casación para la unificación de doctrina preparado por no haber procedido la parte recurrente a la formalización del recurso de casación unificadora en el plazo legal (AATS de 11 de abril de 2019, Rec. 47/18; Rec. 62/18).

b) En el caso de presentación en tiempo y forma del escrito de preparación del recurso de casación para la unificación de doctrina, cuando conste la correcta remisión de un acto de comunicación y transcurran tres días hábiles sin que el destinatario acceda a su contenido, se entenderá que la comunicación ha sido efectuada desplegando plenamente sus efectos, pero como en la jurisdicción social las notificaciones se tienen por realizadas al día siguiente de la fecha de recepción, la notificación se entiende realizada el cuarto día hábil y los plazos comienzan a computar desde el quinto (ATS de 19 de diciembre de 2017, Rec. 37/17).

c) La determinación del día inicial para el cómputo del plazo para la interposición del recurso de suplicación cuando la diligencia de puesta a disposición de los autos se notifica por el sistema LexNet al Letrado designado, que accede a su contenido dentro de los tres días hábiles posteriores, ha de interpretarse aplicando el Acuerdo no jurisdiccional en sus propios términos - si el acceso al contenido de la diligencia de puesta a disposición de los autos se produjo el segundo día hábil concedido para recepcionar la notificación, 
tal resolución debe entenderse notificada el día siguiente hábil, siendo el posterior, el primero del cómputo del plazo de diez días hábiles establecido por el art. 195.1 LRJS para formalizar el recurso de suplicación-: "la apreciación por la sentencia impugnada de que el recurso de suplicación resultaba inadmisible por haberse formalizado extemporáneamente, tomando como dies a quo la fecha en que se considera notificada la diligencia de puesta a disposición de los autos, vulneró los preceptos citados y el derecho a la tutela judicial efectiva de la parte recurrente en su vertiente de derecho de acceso a los recursos legalmente establecidos, como informa el Ministerio Fiscal" (ATS de 19 de junio de 2018, Rec. 638/17).

\section{Bibliografía citada}

- BARRIO CALLE, M.A., "Algunas distorsiones en los actos de comunicación telemáticos en el proceso laboral", Revista Acta Judicial, nº 2, julio, 2018.

- DE LAMO RUBIO, J., “Citación telemática a juicio y nulidad de actuaciones judiciales en el orden social”. Diario La Ley, No 9181, Sección Tribuna, abril, 2018.

- MARTÍNEZ MOYA, J., "Las comunicaciones electrónicas procesales a través del sistema Lexnet y la potestad de control de los tribunales para garantizar el derecho a la tutela judicial efectiva. La tecnología como instrumento al servicio de la justicia y de los justiciables”, Revista de Jurisprudencia Laboral, Núm. 4, 2019.

- MONTOYA MELGAR, A., y otros, Comentarios a la Ley de Procedimiento Laboral, Navarra, Aranzadi, 2003.

- TORRÓ ENGUIX, J., “Aspectos críticos del proceso laboral y el expediente judicial electrónico", Revista de Derecho Social y Empresa, nº 9, septiembre, 2018. 